\title{
ORPHEU ENTRE TRADIÇÃO E VANGUARDA: ECOS DA MELANCOLIA DE ANTÓNIO NOBRE NAS POÉTICAS DE SÁ- CARNEIRO E ALFREDO GUISADO
}

\author{
Fernando de Moraes Gebra ${ }^{1}$
}

Recebido: 28/10/2015

Aprovado: $13 / 12 / 2015$

\begin{abstract}
Resumo: Mário de Sá-Carneiro (1890-1916) e Alfredo Pedro Guisado (1891-1975) escreveram poemas em homenagem àquele que cantou em versos o desencanto com o presente e a saudade de um passado mítico perdido, enlutando-o e figurando-o nos castelos desmoronados por um "vento seco de Deserto e spleen". Trata-se de António Nobre (1867-1900), caracterizado com o seu "olhar doente", em "Só", de Guisado, e como "pajem débil" em "Anto", de Sá-Carneiro, poemas que serão analisados no presente trabalho. A poesia do Modernismo português situa-se em uma relação dialética da tradição simbolista e dos experimentalismos vanguardistas. Encontram-se, pois, muitos ecos da melancolia da poesia de António Nobre nos textos dos jovens de Orpheu, cujas paisagens crepusculares simbolistas parecem pinturas da sensação de aniquilamento do sujeito, que se sente ao mesmo tempo merecedor e deserdado de um bem supremo. Os poemas de SáCarneiro e de Alfredo Guisado serão analisados pelo viés imanentista, considerando seus recursos estilísticos, e também pelo viés intertextual, relacionando a poética desses dois autores com a de António Nobre. Para o estudo das paisagens melancólicas e crepusculares, tomar-se-ão como referentes os estudos de Sigmund Freud, acerca da relação entre literatura e melancolia.
\end{abstract}

Palavras-chave: Modernismo Português; Melancolia; Orpheu; Narcisismo, Intertextualidade.

Orpheu between tradition and vanguard: António Nobre's melancholy echos in SáCarneiro and Alfredo Guisado's poetries.

Abstract: Mário de Sá-Carneiro (1890-1916) and Alfredo Pedro Guisado (1891-1975) wrote poems in tribute to who sang in verses the disenchantment with the present and longing for a mythical lost past, grieving it and figuring it in the castles collapsed by a "dry desert wind and spleen". This verse belongs to António Nobre (1867-1900), featured with his "look sick" in "Só", by Guisado, and as "weak page" in "Anto", by Sá-Carneiro, poems that will be analyzed in this paper. Portuguese Modernism's poetry is located in a dialectical relationship with the Symbolist tradition and avant-garde experimentalism. Therefore, there are many melancholy echoes of António Nobre's poetry in the texts of the young poets from Orpheu generation, whose Symbolist twilight landscapes seem paintings of the feeling of annihilation of the subject. This individual feels at once worthy and disinherited of a supreme good. Sá-Carneiro and Alfredo Guisado's poems will be analyzed by immanentist bias considering their stylistic features, and also the intertextual bias, relating the poetry of these two authors with António Nobre's. For the study of melancholy and crepuscular

\footnotetext{
1 Professor Adjunto III da Universidade Federal da Fronteira Sul, na Licenciatura em Letras-Português e Espanhol, área de Teoria Literária e Literaturas de Língua Portuguesa, e no Mestrado em Estudos Linguísticos, área de Práticas discursivas e subjetividades. Vinculado ao CLEPUL, da Universidade de Lisboa, com pesquisa de Pós-Doutoramento sobre os "esquecidos" da Orpheu.
} 
landscapes, we will take Sigmund Freud's essays about the relationship between literature and melancholy.

Key-words: Portuguese Modernism ; Melancholy; Orphen ; Narcisism, Intertextuality

\section{Introdução}

Na década de 1960, Óscar Lopes foi um dos primeiros historiadores da Literatura Portuguesa a chamar a atenção para a figura literária de Alfredo Pedro Guisado e a considerá-lo "O mais injustamente esquecido dos poetas de Orpheu" (1966, p. 715). A afirmação é contundente, mas a crítica literária parece que não se tem importado muito com isso nas décadas seguintes. Na edição de inverno de 2015, em pleno ano do centenário da revista Orpheu, da qual Guisado participou financeiramente e com treze sonetos publicados em seu primeiro número, a revista Estante estampou desenhos dos rostos dos protagonistas dessa aventura literária, "esquecendo-se" de Alfredo Guisado.

Objeto de estudo de minha investigação de Pós-Doutoramento, a poética de Alfredo Guisado é lida na sua condição intertextual e dialógica que estabelece com os outros poetas de Orpheu, com uma tradição literária simbolista, decadentista e saudosista, e uma tradição historiográfica de ressignificação dos mitos pátrios portugueses. No diálogo com os simbolistas, alguns críticos chegam a afirmar, sem um cotejo intertextual, porém, a influência de António Nobre, sobretudo no primeiro livro de poemas de Guisado, o Rimas da noite e da tristęa (1913), os quais, afirma António Apolinário Lourenço, foram "Redigidos dentro de uma linha discursiva neorromântica, onde se sentem ecoar as vozes de António Nobre e Rosalía de Castro [...]” (2015, p. 286).

No discurso crítico de Apolinário Lourenço, destaco a expressão "ecoar as vozes". Tal como no poema "Só", objeto de estudo do presente artigo, em cuja espacialização ecoam os passos do espectro de Nobre, a poesia de Guisado recebe influxos desse poeta não apenas nesse poema, mas também em outros. Além dos influxos de Nobre, a poética de Guisado dialoga com a de Mário de Sá-Carneiro. Nas duas cartas de Sá-Carneiro a Guisado, publicadas por Arnaldo Saraiva, ressalta a grande admiração do primeiro pelo segundo, perceptível em trechos como "todo o meu entusiasmo pelo seu 'Choro de Maria”, e "o meu entusiasmo pelos seus sonetos" (SÁ-CARNEIRO apud SARAIVA, 1977, p. 69). Embora Sá-Carneiro prefira essas novas composições, escritas em julho de 1914, não deixa de reconhecer os méritos do livro Distância, que fora publicado anteriormente, 
em princípios daquele ano: "A Distância é um belíssimo livro - e, em todo caso, como você é hoje maior do que o Poeta que a escreveu" (ibidem).

\section{1. “Anto” nos ângulos geométricos de Sá-Carneiro}

Feitas essas considerações preliminares, retorno à carta de 20 de julho de 1914 (1977, p. 72-73). Em um passo dessa missiva, Sá-Carneiro comenta ter feito "duas quadras lepidópteras para qualquer poesia futura” (idem, p. 72). Trata-se da segunda e da terceira estrofe que comporão o poema "Ângulo", publicado no primeiro número da Orphen em março de 1915 e que integrará o livro póstumo Indícios de oiro. O cotejo da primeira versão das quadras com o da que foi publicada na Orphen permite perceber algumas mudanças, das quais considero importante a substituição de "ó nau perdida" por "ó nau de festa".

É precisamente neste momento da apresentação que entram as contribuições de Sigmund Freud ao tratar da melancolia e da mania como estados patológicos do indivíduo, relativos a uma perda inconsciente do objeto amoroso e um consequente regresso da libido ao próprio sujeito, em uma atitude narcisista. Freud considera a presença de sentimentos opostos de amor e ódio, que tão bem se representam nas figurações de um eu que quer atravessar uma ponte e um eu que fica estático no cais, no poema "Ângulo", de SáCarneiro, e que são chamados na Psicanálise de "conflito da ambivalência" (FREUD, 2010, p. 184). Freud concorda com Otto Rank que a melancolia tem uma base narcisista: "Tal substituição do amor objetal pela identificação é um mecanismo importante nas afecções narcísicas" (idem, p. 182). Nota-se (e isso vários críticos já amplamente discutiram) uma predisposição ao narcisismo nas poéticas de Nobre e de Sá-Carneiro.

No número especial da revista coimbrã $A$ Galera, dedicada à memória de António Nobre, no qual também publicaram Alfredo Guisado e Fernando Pessoa, Mário de SáCarneiro deu à estampa um dos poucos poemas compostos no ano de 1915, “Anto". Após um período sem produzir (outubro de 1914 a fevereiro de 1915), "É sob o signo de Nobre que recomeça a escrever", conforme postula Fernando Cabral Martins: "É de se notar, a este respeito, que é sobre Nobre o seu único poema-sobre-o-poema” (1997, p. 78). Seguindo a linha de interpretação de Maria da Graça Carpinteiro, Cabral Martins afirma a “enunciação oral” (ibidem) presente nesses últimos poemas de Sá-Carneiro, que o aproximariam da dicção poética nobreana. Especificamente sobre o poema "Anto", Cleonice Berardinelli afirma tratar-se de "um verdadeiro retrato poético de António Nobre, 
de quem Sá-Carneiro, nos últimos versos, bastante se aproximou" (apud SÁ-CARNEIRO, 2005, p. 43).

Anto

Caprichos de lilás, febres esguias, Enlevos de ópio - Íris-abandono... Saudades de luar, timbre de Outono, Cristal de essências langues, fugidias...

O pajem débil das ternuras de cetim, O friorento das carícias magoadas; O príncipe das Ilhas transtornadas Senhor feudal das Torres de marfim...

As aproximações entre o poeta de Indícios de oiro e o de Só evidenciam-se em circunstâncias biográficas e temáticas, principalmente, e em alguns casos, estilísticas. Tanto um como o outro podem ser considerados outsiders, inadaptáveis ao sistema préestabelecido. Embora Nobre não fizesse tantas ousadias morfológicas e sintáticas como SáCarneiro, nota-se aqui e acolá alguns desses elementos da poética simbolista, sobretudo as maiúsculas (essas em grande quantidade) e as sinestesias, como se vê em "Febre Vermelha”: “Flores em brasa! Órgãos da cor! Tirava/ Óperas d’oiro [...]” (NOBRE, 2010, p. 97).

O poema dedicado a António Nobre, lido por Cleonice Berardinelli como um verdadeiro retrato do poeta de Só, poderia também ser compreendido como um inventário das imagens recorrentes em sua poética. Como se vê, não há verbos ao longo dos oito versos do poema, como se Sá-Carneiro, em seu ateliê sinestésico de cores, fizesse um retrato a óleo daquele que também faleceu muito jovem. Das imagens recorrentes na poética nobreana, destacam-se "febres esguias", "Saudades", "luar", "Cristal", "Outono" (primeira estrofe), "friorento", "Senhor feudal", "Torres de marfim" (segunda estrofe), além da temática do eterno desencontro do eu com o outro, como se vê pelas "carícias magoadas" e pela vestimenta do "pajem débil das ternuras de cetim". A hipersensibilidade de Sá-Carneiro parece encontrar eco na de Nobre, na sensação friorenta dessas carícias que, ao invés de protegerem o sujeito, acabam por magoá-lo, por imprimir-lhe a sensação de "Íris-abandono". Ambos os autores, em suas vidas e em suas obras, sentiram-se 
abandonados. Acreditavam serem fadados a um destino alto, mas também marcados pela dor e sofrimento, tal como proposto por Sigmund Freud no processo da melancolia.

Do caleidoscópio de imagens do poema "Anto", algumas sugerem paisagens, atmosferas "fugidias", com certa imprecisão espacial, como "luar", "Outono", "Ilhas transtornadas" e "Torres de marfim". A primeira figura, o luar, apresenta uma importância capital no livro Só, que é composto de várias seções, das quais duas se intitulam precisamente "Lua cheia" (oito poemas) e "Lua quarto-minguante" (sete poemas). A natureza dúbia da lua corresponde à figura do "Esfinge Gorda", presente em "Aqueloutro" (2005, p. 68), de Sá-Carneiro: esse "dúbio mascarado" (ibidem). Na poética de Nobre, a lua cheia funciona como essa atmosfera de plenitude, enquanto a lua quarto-crescente desmascara o seu caráter ilusório.

Encontra-se, pois, nas poéticas de António Nobre e de Sá-Carneiro uma ilusão de plenitude, marcada em Nobre pela figura da lua cheia e em Sá-Carneiro pelo oiro e também pelos entorpecentes, como é o caso de "Enlevos de Ópio", que precede a figura de "Írisabandono". Como forma de suportar a melancolia, gerada pelo abandono e perda do objeto erótico, destaca-se o uso de entorpecentes - os "paraísos artificiais" de muitos poetas simbolistas -, que permitem, ainda que provisoriamente, uma fuga da realidade cotidiana. Ainda que inconsciente das causas que levaram a uma superação provisória da melancolia, o sujeito experimenta uma suspensão do gasto de energia de repressão (Freud, 2010, p. 188), muitas vezes pela "embriaguez alcóolica” (ibidem), cujos efeitos costumam ser semelhantes aos dos entorpecentes.

O caráter febril ("febres esguias"), presente no poema "Febre Vermelha", de Nobre, marcado por uma irradiação de calor e desejo erótico, acaba por se transformar em "O friorento das carícias magoadas". É de se notar que a primeira estrofe do poema "Anto" apresenta, embora com as figuras do abandono e das saudades, cintilações positivas, como os "caprichos de lilás", "febres esguias", "timbres de Outono" e "cristal de essências". Todavia, essas figuras apresentam-se sob o signo da dualidade que a figura da lua expressa. Há de se considerar, também, a mutabilidade de suas quatro fases, o que permite entrever o percurso que vai da plenitude com a lua cheia à queda com a quartominguante.

No poema "Anto", a queda prefigura-se com uma atmosfera mais friorenta e pode ser marcada por figuras como "friorento das carícias magoadas", a acentuar a sensação 
térmica de frio, em oposição ao quente das "febres esguias". Se a primeira estrofe do poema configura a paisagem de António Nobre, a segunda apresenta o que Cleonice Berardinelli chama de "epítetos nobiliárquicos" (2005, p. 43), pois se referem ao sujeito: "o pajem", “o friorento", "o príncipe", "Senhor feudal". O narcisismo que emana de muitos poemas de Nobre, notadamente "Memória", no qual se profetiza seu alto destino - "Serás um Príncipe! mas antes... não fosses” (2010, p. 21) - , acaba por confiná-lo em um universo requintado: "Senhor feudal das Torres de marfim..." é o verso que encerra o poema de SáCarneiro em homenagem a Nobre e que contem outro elemento muito frequente na poética do autor de Só: a Torre.

A "Torre de Anto", antiga fortaleza medieval da cidade de Coimbra e transformada em residência no século XVI, recebeu esse nome atual por ter tido como hóspede António Nobre, que a nomeara em seus poemas como “Torre de Anto". Como se sabe, Anto é uma das várias designações a que Nobre se atribui, como se fosse um desdobramento de personalidade, permitindo certa estrutura dramática de seus poemas, talvez um prenúncio ainda em botão da heteronímia pessoana. Conforme Gaspar Simões, essa torre “comunicava a António Nobre - a 'Anto', o seu castelão - uma como que euforia de épocas passadas" (1939, p. 98).

Ao sentir-se "deslocado na sua época", António Nobre "gostaria de se situar em idos tempos, na Idade Média, com seu pitoresco, com sua auréola feudal, seu nevoeiro místico..." (MALPIQUE, 1964, p. 30), como atesta o último verso do poema "Anto". Ilhados em seus transtornos de grandeza e em suas melancolias de constatação da perda de um passado que já não volta mais, a não ser por pequenos fragmentos de lembranças, o sujeito lírico dos poemas de António Nobre e de Sá-Carneiro parecem entregar-se a atmosferas crepusculares. É o caso da constante reincidência do Outono na poesia de Nobre, que parece antecipar o silêncio e o abismo inevitáveis. Essas figurações da morte encontram numerosas recorrências na poesia de ambos os autores, a tal ponto que ambos chegam a ter uma postura autoirônica em relação ao que Manuel Bandeira chamou de a “indesejada das gentes", como fica patente nos poemas "Balada do caixão" (2010, p. 95), de Nobre, e "Fim" (2005, p. 68-69), de Sá-Carneiro.

\section{O "Só" nos espelhos de Alfredo Guisado}


À memória de António Nobre

Vejo-o passar no desmaiar do Dia...

Mantos azuis arrasta na alameda...

$\mathrm{E}$ a suas mãos crismadas de agonia

Desce um silêncio adormecendo seda...

Seus versos, o ruído de seus passos

Sobre lajedos-alma adormecidos,

Um entreabrir de reposteiros lassos

Em galerias de palácios idos...

Dança em redor o seu olhar doente.

Pastoreia os seus versos no Poente.

Sinto-o passar... É um pastor cansado.

Veste Saudade ante um dormir de espelhos.

Pajem de luto entre noivados velhos

Passa de noite em salas de brocado.

Dedicado "À memória de António Nobre", o soneto em versos decassílabos "Só" (GUISADO, 1969, p. 144), além de estabelecer um evidente jogo intertextual com o que Nobre chamava de "o livro mais triste que há em Portugal” (2010, p. 22), oferece uma imagem espectral do Poeta a vaguear por "galerias de palácios idos". Tal como ocorre na poética de Nobre, os espaços preferenciais da poética guisadiana situam-se em paisagens de tapeçaria, em castelos e em palácios que remontam a experiências longínquas, próximas do medieval. No poema "Só", a espacialização representa-se pelas seguintes figuras: "alameda", "galerias de palácios idos" e "salas de brocado". Dos objetos contidos nesses espaços, destacam-se "lajedos-Alma" e "dormir de espelhos". De maneira especular, mas com outros recursos poéticos, Guisado dialoga com a poética de Nobre. O passado é, em Nobre, a fonte de regeneração que o decadente presente não lhe pode dar: "(E assim me iluda, e assim cuide viver/ Noutro século em que eu deveria nascer)” (2010, p. 50).

Acerca dessa evocação melancólica do passado, assinala Gaspar Simões que "A saudade portuguesa é o refúgio de uma angústia metafísica que se ignora a si mesma" (1939, p. 31). No caso da literatura portuguesa, essa angústia que Heidegger entendia como "elemento fundamental a toda aspiração metafísica" (ibidem), manifesta-se não de maneira abstrata, mas sim nos elementos deste mundo como os amores impossíveis, aspirações desmedidas e saudades. "Saudades de tudo": escreve António Nobre em um poema precisamente intitulado "Saudades", ou seja, saudades de algo que não se sabe conscientemente o que é, gerando essa angústia metafísica, ou ainda, a melancolia, derivada 
do luto, mas relacionada à perda de um objeto (ou de vários objetos) dos quais o sujeito muitas vezes nem tem consciência.

A atmosfera do poema "Só", de Guisado, é carregada dessas tintas melancólicas, como se vê pelas seguintes figuras: "desmaiar do Dia...", "arrasta na alameda", "crismadas de agonia", "reposteiros lassos", "palácios idos", "olhar doente”, "pastor cansado", "Veste Saudade", "Pajem de luto", "noivados velhos". O cansaço existencial do "pastor cansado", ao arrastar os mantos azuis na alameda, mantos estes que o cobrem de Saudade e também de luto, parece ser diagnosticado pelo eu-lírico como "olhar doente". Das imagens melancólicas do poema de Guisado, algumas parecem incidir diretamente sobre o tempo presente: "desmaiar do dia" e "versos no Poente" correspondem ao crepúsculo muito cantado por Nobre.

No conhecido "Poentes de França" (NOBRE, 2010, p. 98-99), ocorre a simultaneidade de duas vozes opostas, uma que afirma os poentes de França e outra que parece emergir do fundo nostálgico do eu que afirma "Eu amo os poentes, mas sem agonias" (idem, p. 99). A bivocalidade de muitos poemas de Só permite a contraposição de uma paisagem crepuscular decadente e agônica da urbe a uma paisagem campestre, de onde emanaria a possibilidade de regeneração do ser humano inquieto. No poema de Guisado, a figura espectral de Nobre é vista com "suas mãos crismadas de agonia". A agonia dos "Poentes de França", referente a essa angústia metafísica, encontra eco nesse poema de Guisado no "olhar doente" que emana do poeta celebrado.

Há de se destacar nesse poema, no que se refere à sua temporalização, a passagem do "desmaiar do dia" e do "Poente" para "um silêncio adormecendo seda...", "lajedosAlma adormecidos", "dormir de espelhos" e, finalmente, a "noite em salas de brocado". Nessas "galerias de palácios idos", o adjetivo posposto ao espaço da enunciação faz referência a uma experiência ancestral, na qual se concentraria o que mais tarde Teixeira de Pascoaes viria a chamar o passado da Raça portuguesa. Tudo no poema de Guisado dorme: o silêncio adormece seda, os lajedos-Alma estão adormecidos, os reposteiros que se entreabrem encontram-se lassos, os espelhos dormem e, finalmente, o pastor de versos, após pastoreá-los no Poente, também se encontra cansado. Dormir parece ser a única maneira de se suportar a realidade, o que se explica o gosto de António Nobre pelas cantigas de embalar, como se vê nos poemas "Ladainha" (2010, p. 121-122) e "O sono de João" (idem, p. 125-127). Neste último, destaco os versos "Há só uma coisa boa, / Que é 
dormir, dormir, dormir..." (2010, p. 26), que mais tarde Sá-Carneiro escreverá em "Vontade de dormir" (2005, p. 23-24): "Fios de oiro puxam por mim" (idem, p. 23), posição corroborada por Fernando Cabral Martins (1993, p. 158).

No poema de Alfredo Guisado, a atmosfera é, pois, de silêncio. Apenas “o ruído de seus passos" contrapõe-se a esse silêncio convidativo ao sono. Os passos desse espectro são sentidos pelo eu-lírico como se houvesse uma proximidade muito grande entre os dois. Os versos "Vejo-o passar no desmaiar do Dia..." e "Sinto-o passar... É um pastor cansado", ambos com reticências - recurso estilístico muito utilizado pela poesia simbolista e também por Sá-Carneiro - permitem afirmar a proximidade entre os poetas António Nobre e Alfredo Guisado. É fundamental perceber que no poema "Só”, os passos de Nobre se sentem em todas as estrofes: "Vejo-o passar" (primeira estrofe), "Seus versos, o ruído de seus passos" (segunda estrofe), "Sinto-o passar" (terceira estrofe), "Passa de noite em salas de brocado" (quarta estrofe). Por mais audíveis que os passos de Nobre estejam no primeiro livro de Guisado, Rimas da noite e da tristeza, em sua obra posterior, esses passos, ainda que muito diluídos e filtrados por outras experiências estéticas, ainda lá encontrarão eco, ou ainda fragmentos especulares.

A figura do espelho é muito recorrente na poética de Alfredo Guisado, como se viu no poema "Só": "Veste Saudade ante um dormir de espelhos". A palavra espelho, do latim speculum, relaciona-se ao verbo "especular", que em António Nobre, aparece como "cismar", como um pensar em demasia, algo quase no nível do patológico. Pathos está relacionado à paixão e a algo que leva à morte, como é o caso do mito de Narciso, que se apaixona pela própria imagem. Clément Rosset deixa isso bem claro, ao apontar que Narciso não se apaixona por si próprio, mas sim por um simulacro que é a imagem refletida:

Porque o espelho é enganador e constitui uma "falsa evidência", quer dizer, a ilusão de uma visão: ele me mostra não eu, mas um inverso, um outro; não meu corpo, mas uma superfície, um reflexo [...]. É por isso que a busca do eu, especialmente nas perturbações de desdobramento, está sempre ligada a uma espécie de retorno obstinado ao espelho: assim a obsessão da simetria sob todas as formas, que repete à sua maneira a impossibilidade de jamais restituir esta coisa invisível que se tenta ver, e que seria o eu diretamente, ou um outro eu, seu duplo exato (1998, p. $80)$.

Se o espelho possibilita o desdobramento do sujeito, tanto em seu lado imanente, como em seu lado manifesto, ou ainda em seus aspectos temporais presente e passado, 
retiro desse último verso citado um importante elemento estrutural da poética de António Nobre: o isolamento no passado. Dito de outra forma, ao vivenciar o tédio no presente e ao perder a confiança no futuro, esgotadas todas as energias vitais do sujeito poético, "[...] só um caminho lhe resta: concentrar-se nas suas lembranças, rodear-se de um passado por todos os lados, edificar à sua volta um dique no qual represe as águas do tempo perdido" (SIMÕES, 1939, p. 59).

\section{Considerações finais}

Como se sabe, a produção literária de cada um dos membros da Orphen deu-se em relações dialógicas, pois cada um deles construiu seu projeto estético-ideológico a partir das muitas conversas que tiveram nos cafés lisboetas e das muitas cartas trocadas, nas quais discorriam acerca de suas produções literárias. É o caso, por exemplo, das cartas brevemente comentadas nesta apresentação, nas quais há uma troca de poemas entre SáCarneiro e Alfredo Guisado, e comentários de um acerca da poesia do outro. Nesse sentido, o estudo de poetas menos conhecidos da geração de Orpheu, como é o caso de Alfredo Guisado, Luís de Montalvor e Ângelo de Lima, justifica-se por ampliar novos pontos de vista acerca do projeto estético-ideológico do primeiro Modernismo português. O objeto principal dessa abordagem consiste em resgatar dos silêncios da historiografia e crítica literárias vozes importantes para a consolidação das estéticas modernistas, em diálogo com a tradição simbolista, decadentista e saudosista.

Os influxos de António Nobre não se fazem presentes apenas nos poemas analisados neste artigo. Em muitos dos poemas de Sá-Carneiro e Alfredo Guisado, encontra-se um sujeito melancólico, que busca preencher os vazios da linguagem, por meio de experimentos linguísticos e criação de paisagens subjetivadas. A travessia do sujeito lírico para outros mundos, nos quais haveria plenitude de sensações e recordações, com a fusão dos níveis temporais do discurso, no encontro com o tempo mítico, pode ser considerada uma resposta à angústia metafísica, resultante da melancolia. Conforme Sigmund Freud, tanto a melancolia como o luto escondem sua agressividade contra o objeto perdido, que é instalado simbolicamente no próprio sujeito, tornando-se um duplo, implicando no paradoxo de amá-lo e odiá-lo.

Como comentado, entendo a melancolia como mola propulsora da despersonalização do sujeito, como se vê pelas imagens espectrais do poema de Guisado e 
das construções nominais e caleidoscópicas do poema de Sá-Carneiro. Não apenas nesses poemas, mas na poética de um e de outro, nota-se o desencanto com o presente e a saudade de um passado mítico perdido, enlutando-o e figurando-o nos castelos desmoronados por um "vento seco de mau sestro e spleen" (NOBRE, 2010, p. 132), como escreve António Nobre em um de seus mais conhecidos sonetos. Caracterizado com o seu "olhar doente" em "Só", de Guisado, e como "pajem débil” em "Anto", de Sá-Carneiro, Nobre faz ecoar nas poéticas desses autores imagens que permitem afirmar que Orpheu não foi apenas ruptura, como muitos críticos assinalam, mas principalmente, diálogo com uma tradição poética e historiográfica. Nesse ano em que se comemora o centenário de Orpheu, devem-se considerar não apenas os aspectos vanguardistas de algumas publicações contidas na revista, mas também o diálogo com a tradição, sem a qual o projeto modernista talvez não fosse plenamente possível. Orpheu dialoga com uma tradição e também perpetua essa mesma tradição. Afinal, nas palavras de Fernando Pessoa, no terceiro número da revista Sudoeste: "Orpheu acabou. Orpheu continua".

\section{Bibliografia}

FREUD, Sigmund. "Luto e melancolia". In: Introdução ao narcisismo, ensaios de metapsicologia e outros textos (1914-1916). Trad. Paulo César de Souza. São Paulo: Companhia das Letras, 2010. p. 170-194.

GUISADO, Alfredo Pedro. Rimas da noite e da tristera. Lisboa: Livraria Clássica, 1913.

Tempo de Orfeu (1915-1918). Com um estudo de Urbano Tavares Rodrigues. Lisboa: Portugália, 1969.

LOPES, Óscar. História ilustrada das grandes literaturas. Literatura Portuguesa. Lisboa: Estúdios Cor, 1966, v.VIII.

LOURENÇO, António Apolinário. "Alfredo Guisado: Um modernista acidental?" In: DIX, Stephen (org.). 1915 - O ano do Orpheu. Lisboa: Tinta da China, 2015. p. 285-296.

MALPIQUE, Cruz. "Traços do perfil de António Nobre entrevistos na sua correspondência". Separata de "Boletim da Biblioteca Pública Municipal de Matosinhos", n.11, agosto de 1964. Matosinhos: Leixões.

MARTINS, Fernando Cabral. Notas sobre a imagem do poeta em António Nobre e Mário de Sá-Carneiro. In: Revista Colóquio/Letras. Ensaio, n. ${ }^{\circ}$ 127/128, Jan. 1993, p. 157-167.

O modernismo em Mário de Sá-Carneiro. Lisboa: Editoral Estampa, 1997.

NOBRE, António. Só. Introdução e notas de Ana Maria Amaro. Porto: Porto Editora, 2010.

RODRIGUES, Urbano Tavares. "Redescoberta da poesia de Alfredo Guisado". In: GUISADO, Alfredo. Tempo de Orfeu (1915-1918). Lisboa: Portugália, 1969. 
ROSSET, Clément. O real e seu duplo: ensaio sobre a ilusão. Apres. e Trad. José Thomaz Brum. Porto Alegre: L\&PM, 1998.

SÁ-CARNEIRO, Mário de. Poesias. Edição de Cleonice Berardinelli. Rio de Janeiro: Agir, 2005. (Nossos clássicos).

SARAIVA, Arnaldo. Cartas de Mário de Sá-Carneiro a Luís de Montalvor, Cândida Ramos Alfredo Guisado, José Pacheco. Porto: Limiar, 1977.

SIMÕES, João Gaspar. António Nobre, precursor da poesia moderna. Lisboa: Inquérito, 1939. (Cadernos Culturais). 